\title{
Técnicas quirúrgicas periodontales aplicadas a la implantología
}

\author{
MATEOS L * \\ LAZARO PJ ** \\ HERRERO $\mathbf{F} * * *$ \\ HERRERO $\mathbf{M} * * * *$
}

\begin{abstract}
Mateos L, Lázaro PJ, Herrero F, Herrero M. Técnicas quirúrgicas periodontales aplicadas a la implantología. Av Periodon Implantol. $2003 ; 15,2: 57-68$.
\end{abstract}

\begin{abstract}
RESUMEN
La similitud morfológica y funcional existente entre los tejidos periimplantarios y los tejidos periodontales ha permitido adaptar técnicas de uso habitual en periodoncia al campo de la implantología. El manejo de los tejidos periimplantarios de forma correcta buscando como objetivo el mejorar el entorno periimplantario, tanto con fines estéticos como para facilitar el correcto mantenimiento, es una práctica habitual hoy en día en la terapia implantológica. El objetivo de este artículo es revisar la bibliografía referente a estos conceptos y las distintas técnicas quirúrgicas empleadas en la terapia periodontal que han sido aplicadas en implantología.
\end{abstract}

\section{PALABRAS CLAVE}

Implantes, injertos encía, manejo tejidos blandos.

\section{INTRODUCCIÓN}

El uso de implantes osteointegrados para reemplazar dientes naturales perdidos está ampliamente documentado y hoy día constituye una opción de tratamiento predecible a largo plazo en diferentes situaciones clínicas (1-4).

Los criterios de éxito sobre la eficacia a largo plazo del tratamiento implantológico definidos por Albrektsson se basaban en conceptos relacionados con la integración entre el implante y el hueso receptor: ausencia de radiolucidez periimplantaria, ausencia de movilidad, pérdida ósea anual tras el primer año menor de 0.2 $\mathrm{mm}$, ausencia de dolor, ausencia de infección y ausencia de parestesias (2). En la revisión realizada por ten Bruggenkate se aprecia que la mayoría de los parámetros manejados por los diferentes autores, son pará- metros de aplicación periodontal (índice de sangrado, profundidad de sondaje, sangrado al sondaje,...) y que permiten la monitorización de forma objetiva del paciente a lo largo del tiempo (5). Mombelli incorpora posteriormente la valoración estética como criterio de éxito a tener en cuenta (6).

La alta predictibilidad de los tratamientos con implantes sumado al aumento en las indicaciones de dichos tratamientos, hace que la frecuencia de los tratamientos con implantes en las localizaciones estéticas sea mayor, además con unas altas demandas por parte de paciente y profesional. En este sentido, los objetivos estéticos en Implantología van encaminados a imitar la naturaleza, creando un perfil que simule la emergencia radicular y manteniendo o reconstruyendo en lo posible las papilas interdentarias, tratando de conseguir una arquitectura gingival correcta $(7,8)$.

* Odontólogo. Alumno Máster en Periodoncia e Implantes. UCM.

** Odontólogo. Máster en Periodoncia. UCM. Profesor colaborador Máster en Periodoncia e Implantes. UCM.

*** Médico-odontólogo. Especialista en Periodoncia. Univ. Aahrus. Profesor colaborador Máster en Periodoncia. UCM.

**** Médico-estomatólogo. Profesor colaborador Máster en Periodoncia e Implantes. UCM. 
Así, la demanda de resultados estéticos por parte del paciente y los objetivos fijados por los profesionales hacen de la implantología una disciplina cuya aplicación es de una gran exigencia. La similitud entre los tejidos periodontales y periimplantarios hacen que distintos conceptos y técnicas periodontales se hayan aplicado a la implantología, como en el caso de la monitorización y los parámetros que la permiten, el mantenimiento, y los conceptos de cirugía plástica periodontal, entre otros.

En suma, las metas en el manejo de los tejidos blandos en implantes deben ser la obtención de un resultado estético lo más adecuado posible y el garantizar unas condiciones ópticas para el mantenimiento de las fijaciones intraóseas.

\section{RELACIÓN ENTRE TEJIDOS PERIODONTALES Y TEJIDOS PERIIMPLANTARIOS}

\section{Tejido epitelial}

James y Kelln comprobaron cómo, tras la cirugía implantológica, el epitelio gingival regeneraba una serie de células epiteliales que eran siempre similares a las células epiteliales del epitelio del surco y del epitelio de unión en los dientes naturales (9). Otras características, tales como la existencia de epitelio queratinizado y la adhesión por hemidesmosomas entre el pilar del implante y el tejido periimplantario, indican que no existen diferencias a nivel epitelial entre ambos tejidos (10).

\section{Tejido conectivo}

Los autores previamente citados ya demostraron la existencia de fibras de tejido conectivo apicales a la interfase epitelial y explicaron el posible papel de estas fibras en la sustentación del epitelio superficial (9). La histología de ambos tejidos fue estudiada por Berglundh y cols, donde observan diversas semejanzas como la ausencia de infiltrado inflamatorio en estado de salud y la presencia de fibras colágenas en ambos tipos de tejido. No obstante, también confirman la existencia de diferencias en cuanto a la cantidad de estas fibras colágenas (mayor número en el tejido periimplantario) y la orientación de estos haces de fibras colágenas, ya que mientras que el tejido gingival supracrestal posee una orientación perpendicular a la superficie dentaria con una altura de unos $3 \mathrm{~mm}$ hasta el margen gingival libre (2 $\mathrm{mm}$ de inserción epitelial y $1 \mathrm{~mm}$ de inserción conectiva desde el cemento radicular), los tejidos periimplantarios tienen sus fibras orientadas de forma paralela a la superficie del implante, con origen en el hueso integrado a las fijaciones (10).
Existen también algunas diferencias estructurales en el tejido periimplantario según esté o no íntimamente unido a la superficie del implante. Los estudios de Moon y cols mostraron cómo en la porción de tejido conectivo en contacto con los pilares transepiteliales apenas existen vasos sanguíneos, pero sí presenta una gran cantidad de fibroblastos interpuestos entre las fibras colágenas; esta circunstancia parece ser responsable de asegurar el mantenimiento de un sellado correcto entre el medio ambiente oral y la superficie del implante. En cambio, la zona de tejido conectivo más alejada del pilar transepitelial presenta comparativamente menos fibroblastos que la anterior, pero a su vez posee más fibras colágenas y más vasos sanguíneos (11).

\section{Función}

Las similitudes estructurales entre ambos tipos de tejidos halladas en los diversos estudios están acompañadas por similitudes en cuanto a la función que éstos desarrollarían, tal como fueron descritas en las conclusiones del Primer Workshop Europeo de Periodoncia (12). Se considera en ese tratado que la interacción entre los tejidos periimplantarios y la superficie de las fijaciones intraóseas suele derivar en una integración del tejido conectivo alrededor del implante, y que ésta desempeña una función muy importante en la prevención de la migración epitelial y establecería así una barrera biológica que garantizaría el éxito del mismo. Cabe destacar este hecho, ya que no ocurre con frecuencia en la naturaleza que dos tipos de tejidos que desarrollan funciones similares posean un origen distinto (recordemos que el epitelio del tejido periodontal proviene del epitelio reducido del esmalte y el epitelio del tejido periimplantario lo hace del epitelio oral tras la curación de la herida quirúrgica).

En cambio, sí existe una similitud al corroborar la existencia del espacio o anchura biológica en dientes e implantes. Berglundh y Lindhe comprobaron cómo la anchura biológica en implantes ocupa un espacio de aproximadamente $3 \mathrm{~mm}$ de espesor (3.17 $\mathrm{mm}$ en dientes y $3.80 \mathrm{~mm}$ en implantes); en el caso de los implantes, este espacio estaba repartido entre $2 \mathrm{~mm}$ de inserción epitelial y $1-1.5 \mathrm{~mm}$ de inserción conectiva. La parte mas coronal del ancho biológico se situaría por debajo de la interfase implante-pilar ó implante-prótesis más próxima a la cresta ósea. Si durante el procedimiento quirúrgico no se respeta el espacio necesario entre la cresta ósea y la interfase más próxima a ésta, se producirá reabsorción ósea hasta conseguir el espacio para la anchura biológica (13).

Por otro lado, es importante reconocer el papel pro- 
tector de la mucosa que recubre la superficie de los implantes en contacto con el medio oral. Lavelle (14) y otros autores han resaltado la necesidad de que la mucosa queratinizada se adapte adecuadamente al implante, formando una barrera al paso de las toxinas orales y las bacterias hacia el surco periimplantario.

En resumen, este precinto biológico que forman los tejidos periimplantarios consiste en la regeneración y adaptación de las células y los tejidos a la superficie de los biomateriales implantados, constituyendo la barrera tisular que protege del paso de microorganismos y toxinas desde el medio oral al interior de los tejidos periimplantarios, y su mantenimiento en estado de salud es fundamental para el mantenimiento de su integridad (15).

\section{Microbiología}

Las características de la flora bacteriana son muy similares en ambos tipos de tejidos tanto en condiciones de salud como en enfermedades. Existe una flora compuesta predominantemente por cocos y bacilos no móviles Gram + en condiciones de salud, apareciendo colonias de bacterias anaerobias Gram-, bacilos móviles y espiroquetas de forma dominante cuando existe una situación patológica, tanto en los tejidos periodontales como en los periimplantarios $(16,17)$.

\section{CONSIDERACIONES EN EL MANTENIMIENTO DE LOS IMPLANTES: LA MUCOSA QUERATINIZADA}

Establecida la importancia de esta barrera biológica, el punto a analizar sería la necesidad de que en este precinto tisular exista o no mucosa queratinizada. En general, se admite la idea de que la mucosa queratinizada no constituye un requisito imprescindible para asegurar la salud tanto en denticiones naturales como alrededor de los implantes dentales $(18,19)$.

En el caso de los dientes, el periodonto mantiene siempre una banda mínima de encía queratinizada, de $0.5 \mathrm{~mm}$ aproximadamente, debido al potencial inductor del ligamento periodontal, característica que en el caso de los implantes no se produce por la ausencia de este ligamento periodontal $(20,21)$.

Desde un punto de vista clínico, las restauraciones se higienizan de una manera más fácil y confortable cuando existe una adecuada banda de mucosa queratinizada alrededor de los implantes. De hecho, algunos estudios han demostrado que existe una mayor recesión y más pérdida de la inserción en los implantes sometidos experimentalmente al efecto de la placa bacteriana cuando éstos están rodeados de mucosa no queratinizada respecto a aquellos caso en los que se proveía de una banda adecuada de mucosa queratinizada (22). Esto lleva a la conclusión de que existe una condición más favorable para el mantenimiento de los implantes cuando existe una cierta cantidad de tejido queratinizado alrededor de las fijaciones.

Según Warrer la banda de mucosa queratinizada adecuada parece ser de al menos $2 \mathrm{~mm}$ de anchura alrededor de los implantes $(10,22,23)$.

\section{OBJETIVO}

El objetivo de este artículo es revisar la bibliografía referente a los conceptos y las distintas técnicas quirúrgicas de uso en periodoncia que han sido aplicadas al campo de la implantología en sus distintas fases terapéuticas.

\section{MANEJO DE TEJIDOS PERIIMPLANTARIOS. FUNDAMENTOS Y OBJETIVOS}

La manipulación quirúrgica de los tejidos blandos periimplantarios en la cirugía implantológica, independientemente del momento en que se realice, busca dos objetivos principales: 1 . Obtener un resultado estético lo más adecuado posible y 2. Garantizar unas condiciones óptimas para el mantenimiento en estado de salud del tratamiento a largo plazo.

\section{LOCALIZACIÓN DE IMPLANTES}

Según la zona edéntula que se esté rehabilitando, se debe diferenciar entre localizaciones estéticas y localizaciones estándar.

1. Localizaciones estéticas comprenden los implantes colocados en áreas con prioridad estética, siendo ésta la zona de máxima exposición dentaria de cada paciente.

2. Por localizaciones estándar se entiende aquellos implantes colocados en áreas sin compromiso estético, donde la función y el mantenimiento serán nuestros objetivos principales (24). 


\section{MOIMENTOS QUIRÚRGICOS}

Para establecer un orden con el fin de comentar las distintas posibilidades terapéuticas en cada etapa del tratamiento nos serviremos de los tiempos de actuación que distinguen Hurzeler y Dietmar (25), Bahat y cols (26) y otros autores. Así, comentaremos las opciones de manejo de tejidos que se realizan I- antes de la inserción de los implantes, II- en el momento de la inserción (primera fase quirúrgica), III- durante la segunda cirugía, IV- aquellos procedimientos que se llevan a cabo en la fase de mantenimiento.

\section{VARIACIONES SEGÚN TIPOY TÉCNICA DE IMPLANTES}

Además del análisis de los momentos de actuación en función de la fase de tratamiento en que se instaure, las opciones terapéuticas también dependen del tipo de procedimiento implantológico empleado: una técnica sumergida o bien no sumergida, así como los tipos de implantes usados: en una sola pieza o en dos piezas.

\section{Implantes de una pieza con técnica no sumergida (una fase)}

En estos casos existe un momento quirúrgico, el mismo en el que se inserta el implante, pues esta técnica evita la segunda cirugía al permanecer parte de la fijación en comunicación con la cavidad oral desde el momento de la inserción.

\section{Implantes de dos piezas con técnica sumergida (dos fases).}

En ella el implante es insertado en el hueso receptor y recubierto en su totalidad por el tejido blando presente en el colgajo quirúrgico. Un primer momento para actuar sobre los tejidos blandos es aquel en el que se coloca el implante, existiendo una segunda oportunidad para actuar sobre los tejidos en la cirugía de conexión de los pilares transepiteliales, una vez transcurrido el período de osteointegración.

Las distintas casas comerciales ofrecen al implantólogo la posibilidad de utilizar fijaciones intraóseas de una o dos piezas. La posición en la que quede la interfase implante-pilar (gap) es determinante para la estructuración de los tejidos blandos periimplantarios $(10,27,28,29)$. Podremos ubicar esta interfase en distintas posiciones (más alto o más bajo) modificando nuestro protocolo de inserción en la cirugía.
Normalmente, los implantes de dos piezas se insertan con técnica sumergida, mientras que los de una pieza se realizan en una sola fase (técnica no sumergida). No obstante, y en función de los objetivos terapéuticos evaluados en la fase diagnóstica, los implantes de dos piezas pueden colocarse en una sola fase dejando expuesta a la cavidad oral el pilar de cicatrización; asimismo, los implantes de una pieza pueden cubrirse completamente dentro del colgajo en la cirugía de inserción, de forma que permitan un mejor manejo de los tejidos blandos.

\section{OBJETIVOS DEL MANEJO DE TEJIDOS BLANDOS}

\section{Estética}

Los fundamentos estéticos están relacionados con el área de máxima exposición dentaria de cada paciente; de esta forma somos capaces de individualizar cada caso en función de los requerimientos de cada individuo.

En general, nuestro objetivo será el imitar a la naturaleza, intentando para ello conseguir que el entorno de la restauración posea las siguientes características $(30,31,32)$ :

a. Aspecto de eminencia radicular, otorgando a nuestra restauración una imagen visual de crecimiento natural a partir de los tejidos blandos.

b. Arquitectura gingival armónica, intentando imitar la posición natural de los cenit (puntos más apicales del margen gingival libre) gingivales en la sonrisa en presencia de dientes naturales.

c. Tejidos blandos periimplantarios que imiten a las papilas dentales.

La obtención de un adecuado marco de la restauración se consigue merced a una adecuada relación tridimensional entre la restauración y el implante, siendo por tanto de capital trascendencia la posición en que se sitúa el implante en la cresta ósea en función de las necesidades restauradoras.

\section{Mantenimiento}

La fase de mantenimiento en implantología es clave en el éxito del tratamiento, y debe ser un objetivo, en la planificación de los casos, obtener unas condiciones óptimas que favorezcan las medidas higiénicas por parte tanto del paciente como del profesional. 


\section{PROCEDIMIENTOS QUIRÚRGICOS. TIEMPOS DE ACTUACIÓN}

1. Previo a la inserción de las fijaciones intraóseas

Se realizan sobre todo actos terapéuticos sobre los tejidos duros de los maxilares, intentando conseguir un aumento en el volumen de la cresta ósea para insertar los implantes en la posición adecuada cuando llegue el momento. Se han aplicado distintas técnicas quirúrdas, reconstruyendo el reborde alveolar y aumentando así la predictibilidad de nuestro tratamiento.

En el momento de aplicación de estas técnicas prima como objetivo el aumento de volumen óseo en la cresta desdentada. Los tejidos blandos se modificarán con el fin de obtener éxito en las técnicas de Regeneración Osea aplicadas. Esta alteración será corregida con posterioridad, devolviendo a la cresta edéntula las dimensiones correctas para llevar a cabo la rehabilitación. En las situaciones donde la deformidad de la cresta no haga necesaria la regeneración de tejidos duros, se puede restaurar el contorno bucal aumentando el espesor del mismo, de forma que mejoremos el futuro perfil de emergencia de nuestras gicas con el objetivo de recrear las estructuras perdi-

restauraciones (26). Las técnicas quirúrgicas utilizadas aquí se han empleado previamente para solucionar tanto defectos mucogingivales (cubrimientos radiculares) como para devolver el contorno original a rebordes parcial o totalmente edéntulos $(33,34,35)$.

\section{TÉCNICAS QUIRÚRGICAS}

En esta fase del tratamiento se usan fundamentalmente autoinjertos de tejidos blandos procedentes de la mucosa masticatoria del paladar, bien epitelizados 0 subepiteliales.

a. El injerto libre de tejido palatino epitelizado consiste en transferir una porción de tejido palatino (conectivo más epitelio) al área receptora. Es una técnica muy predecible, que tiene su mayor inconveniente en las molestias que ocasional dejar una zona cruenta en el paladar tras la obtención del injerto (Fig. 1-4). Utilizaremos estas técnicas con los siguientes objetivos (36):

- Aumento del volumen en sentido apico-coronario (devolviendo a su posición la línea mucogingival
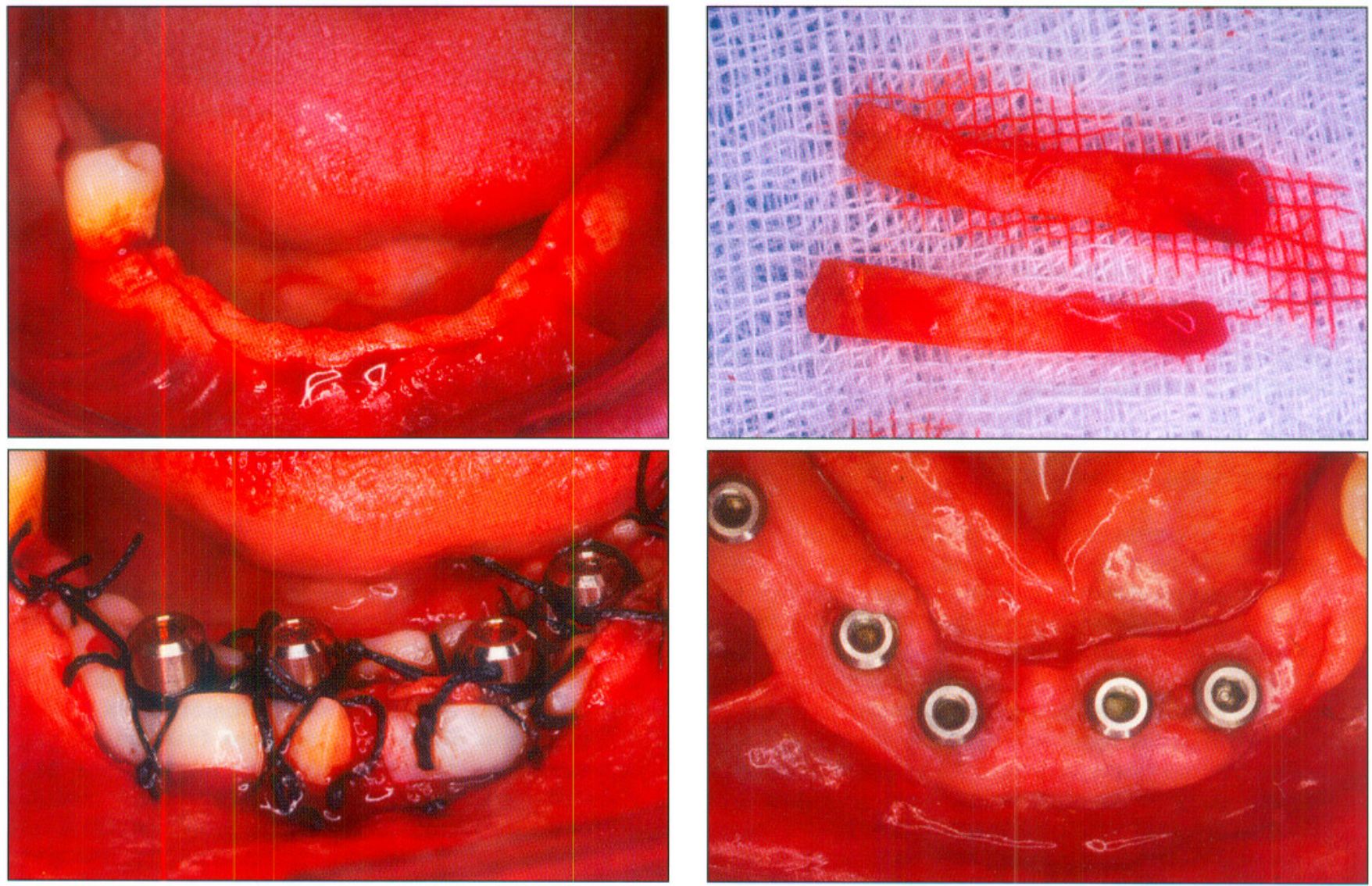

Fig. 1-4: Injerto palatino epitelizado colocado durante la cirugía de inserción de implantes con el fin de obtener una banda de mucosa queratinizada alrededor de los pilares. 


\section{AVANCES}

Volumen 15 - No 2 - Agosto 2003
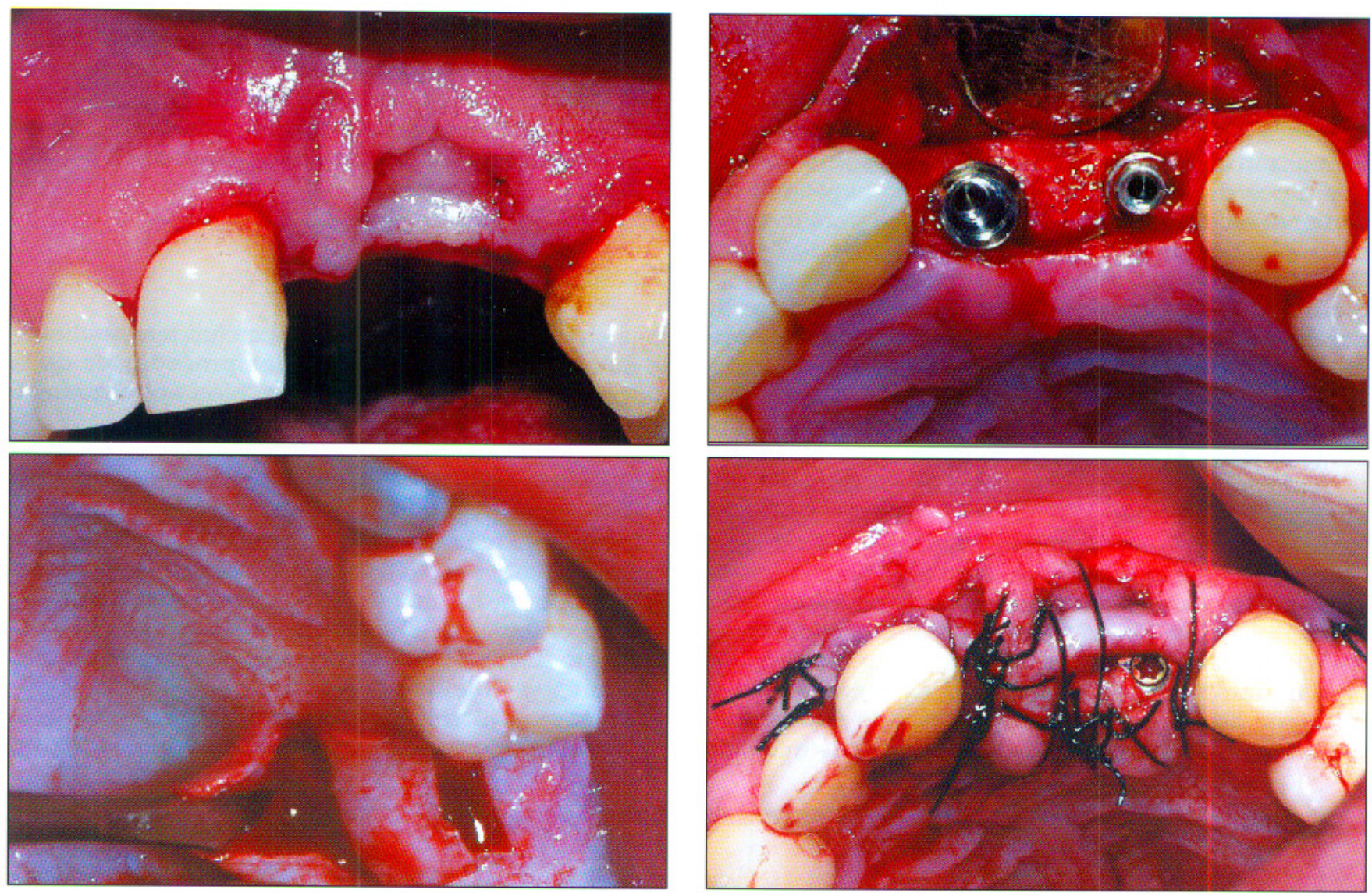

Fig. 5-8: Injerto conectivo subepitelial y de conectivo epitelizado de interposición durante la cirugía de colocación de implantes con aumento de la cantidad de tejido blando por vestibular. El objetivo es mejorar el perfil de emergencia de la restauración final.

en aquellos casos donde previamente había sido desplazada coronalmente para cubrir los injertos de tejidos duros).

- Emparejar rebordes con profundas fisuras o con brechas del tejido blando.

- Enmascarar decoloraciones de los tejidos, como tatuajes de amalgama, etc.

b- El injerto conectivo subepitelial descrito por Langer (34) para recubrimientos radiculares tiene una aplicación directa en estas situaciones previas a la cirugía implantológica. En esta técnica no se toma todo el epitelio correspondiente al injerto en el área donante, lo que disminuye las molestias en la cicatrización antes descritas, además de permitir obtener mayores cantidades de tejido con un menor trauma postoperatorio. La aplicación de esta técnica para aumentar la anchura y altura del reborde alveolar requiere la introducción del injerto en una bolsa subepitelial creada por vestibular de la cresta, donde se modela para formar el contorno deseado (Fig. 5-8) (37).

\section{Durante la cirugía de inserción de los implantes}

Los objetivos en esta fase del tratamiento son: 1. preservar el tejido blando existente y 2. mejorar el resultado estético final de la restauración implantosoportada.

\section{TÉCNICAS QUIRÚRGICAS}

a. Cicatrización gingival guiada. Descrita por Reiser (38), este concepto está basado en orientar la cicatrización de los tejidos blandos periimplantarios para actuar sobre la morfología de los mismos. Para ello, se toma una impresión de la cabeza del implante durante la primera fase quirúrgica; con esta impresión se realiza una restauración provisional que se insertará en la segunda cirugía, logrando un perfil de emergencia adecuado a través de las distintas modificaciones necesarias en la restauración. Una vez conseguido éste, se realiza la restauración definitiva (Figs. 9 y 10) (39). 


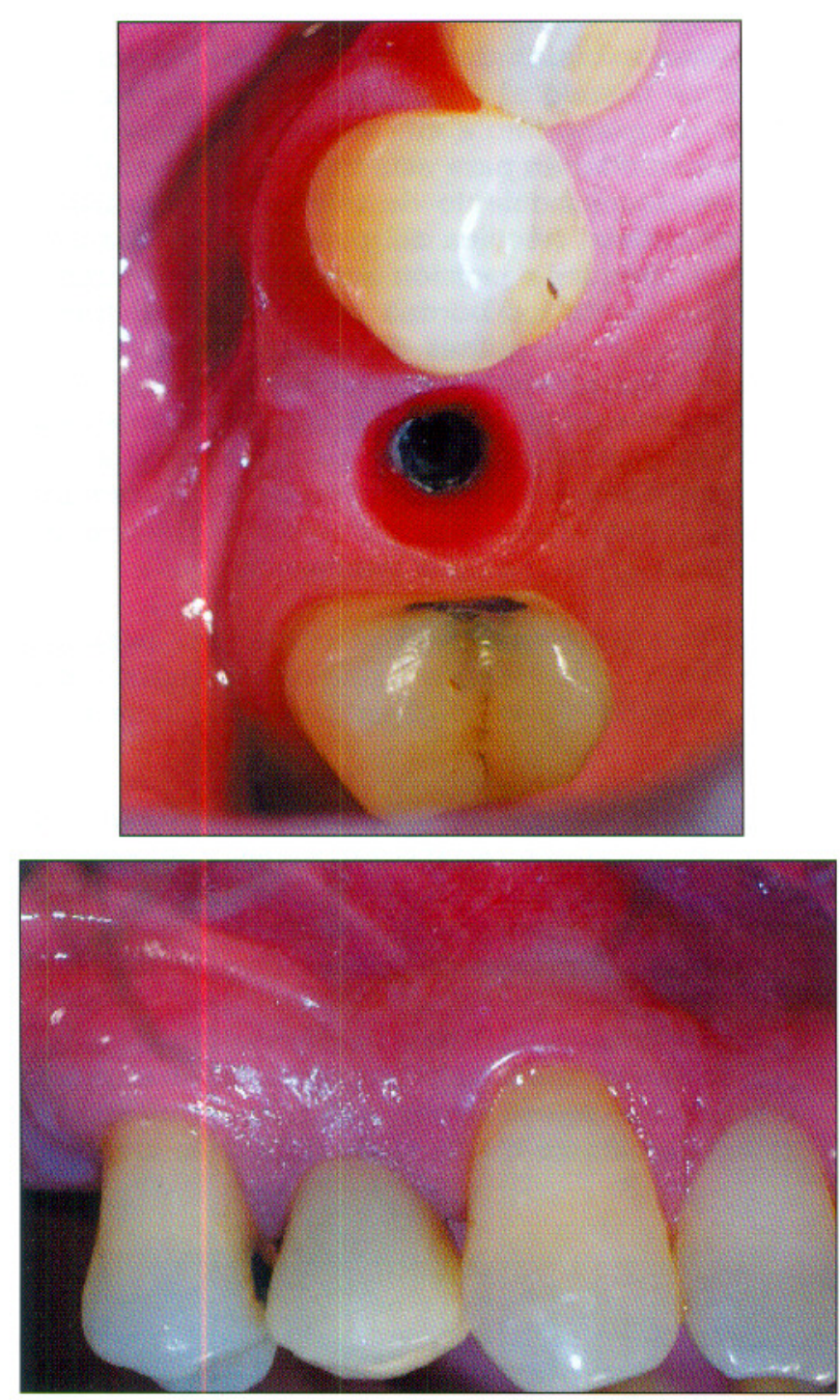

Fig. 9 y 10: Cicatrización Gingival Guiada por la prótesis provisional, mejorando el perfil de emergencia de la restauración.

\section{b. Técnicas quirúrgicas con desplazamiento de} tejidos. Se utilizan en esta fase quirúrgica sobre todo en el maxilar superior, ya que se ofrece una gran cantidad del tejido a desplazar desde el área palatina, situación que es difícil de reproducir en la mandíbula.

- Colgajo palatino deslizante. Descrito por Tinti y cols (40). Este colgajo permite, merced a su posicionamiento coronal, no sólo cubrir membranas usadas en la cirugía de inserción de implantes, sino también aportar encía queratinizada alrededor de los implantes cuando se realiza correctamente durante la segunda intervención quirúrgica implantológica.
- Técnicas del conectivo alveolar (TCA) descrita por Diví (41), que adapta los conceptos de la técnica conocida como "roll technique" ideada por Abrams (42), con el fin de aprovechar el tejido conectivo del interior del alveolo. La TCA se utiliza en la cirugía de inserción de implantes inmediatos tras la exodoncia de dientes unirradiculares y la maduración de los tejidos blandos; consiste en realizar la incisión buscando el reborde óseo palatino del alveolo post-exodoncia, desplazando hacia vestibular el tejido conjuntivo alveolar junto con el colgajo mucoperióstico, doblándolo sobre sí mismo a fin de aumentar el volumen en esta zona. Esta técnica permite no sólo preservar la reabsorción del hueso alveolar, sino que también aporta una cantidad importante de tejido blando por bucal de la futura restauración protésica.

c. Inserción de implantes inmediatos. Manejo de tejidos blandos. Cuando una raíz es sustituida por un implante sólo una porción del implante está en íntimo contacto con la superficie ósea. Rosenquist (30) comparó varios métodos para manejar los implantes inmediatos:

- Plastia de Rehrman: se realiza una incisión en el periostio de la base del colgajo vestibular para traccionar así del colgajo y cubrir el espacio que deja el diente extraído;

- Injerto gingival libre, cubriendo esta zona crítica sin necesidad de elevar un colgajo;

- Colgados pediculados sobre la encía querantinizada vestibular, que son posteriormente posicionados y suturados en el alveolo cerrando la herida vestibular al final de la intervención. Aunque el objetivo primero de este procedimiento es conseguir un cierre primario del alveolo, existen trabajos que indican la posibilidad que existe en estos diseños de colgajo para colocar membranas, desplazar los tejidos y cubrir posibles defectos óseos y/o mucogingivales $(43,44)$.

- Cirugía de sellado alveolar. Consiste en realizar la inserción del implante a través del alveolo y cubrirlo con un autoinjerto de tejido palatino epitelizado. Esta adaptación técnica fue descrita por Landsberg como una opción terapéutica que minimiza el trauma y mejora los resultados estéticos (45). Este autor analiza el procedimiento quirúrgico y las ventajas que posee, entre ellas la inserción del implante en posición idónea guiada por el orificio del alveolo, la prevención de la posible contaminación bacteriana al sellar el sitio quirúrgico del medio oral, además de preservar tanto el componente óseo como el tejido blando periimplantario, incluyendo las papilas. Esta técnica faci- 


\section{AVANCES}

Volumen 15 - $\mathrm{N}^{\circ} 2$ - Agosto 2003

lita también la segunda fase quirúrgica, en tanto que minimiza el trauma al exponer directamente los implantes en esta cirugía de conexión sin necesidad de elevar un colgajo, utilizando si es posible técnicas de punch o bisturí eléctrico, lo que redundará positivamente en el resultado estético del caso (46).

d. Técnicas de Regeneración Ósea Guiada. Se utilizan en esta primera cirugía de implantes para aumento de volumen de la cresta. Al realizar esta técnica simultáneamente a la colocación de implantes se reducen el número de intervenciones, así como el tiempo y el costo del tratamiento.

\section{Durante la cirugía de conexión de los pilares transepiteliales}

Esta fase del tratamiento tiene como objetivo conectar a los implantes los pilares transepiteliales; para muchos autores este es un momento idóneo para acceder y actuar sobre los tejidos periimplantarios $(47,48)$. Llegados a este momento, debemos valorar la necesidad de aumentar mediante injertos de tejidos blando el volumen de los mismos. En el caso que este aumento de tejido no sea necesario, se buscará mejorar el entorno de los implantes desde el punto de vista de la función. A este respecto, Hertel y cols diferencian las técnicas excisionales de las técnicas incisionales (48): a. Técnicas excisionales; eliminan el tejido sobre el implante usando el bisturí, punch, electrobisturí o fresas de grano fino a alta velocidad. Inicialmente se recomendaban para esta fase técnicas quirúrgicas sin desplazamiento de tejidos, bien usándole bisturí circular (técnica del punch) o bien realizando una pequeña incisión supracrestal, suturando posteriormente los bordes bucal y lingual tras la conexión de los pilares de cicatrización (49). En general, las técnicas excisionales permiten poca movilización de los tejidos blandos, por lo que estas técnicas quedan reservadas para los casos en los que existe suficiente cantidad de tejido queratinizado en la zona a exponer y cuando el objetivo sea minimizar el trauma de la intervención (47).

b. Técnicas incisionales; son técnicas que permiten el manejo de los tejidos blandos periimplantarios tras la elevación de colgajos. Destacan entre estas técnicas:

- Colgajo de reposición apical. Consiste en realizar una incisión supracrestal sobre mucosa queratinizada para despegar un colgajo mucoperióstico y desplazarlo hacia apical, recubriendo todo el perímetro del pilar con este tipo de mucosa (Fig. 11-13).

\section{- Colgajo trapezoidal con preservación de papi-} las. Se realiza una incisión supracrestal en forma de trapecio que se sutura por vestibular, y que se utiliza habitualmente en casos de implantes unitarios.
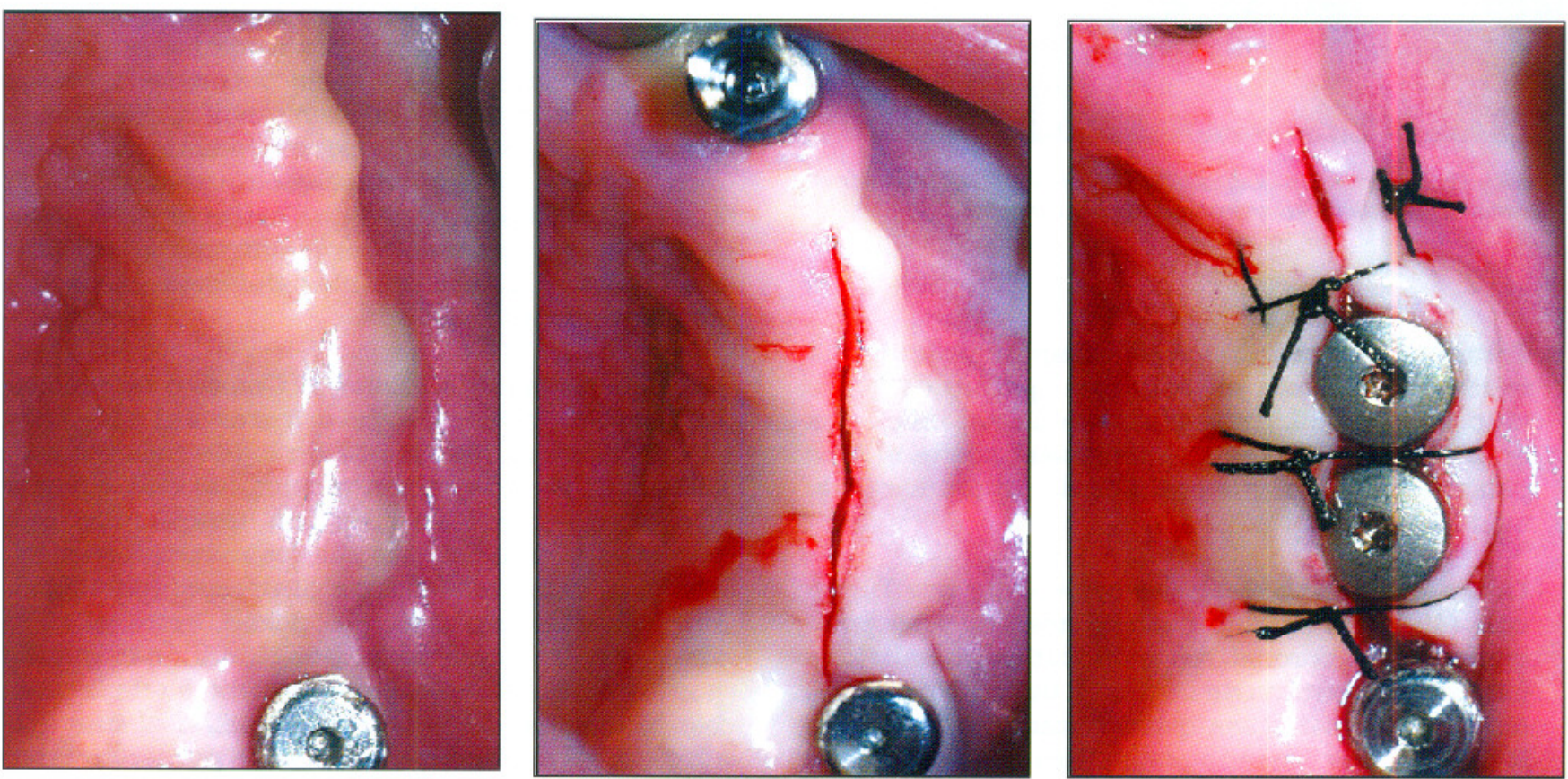

Fig. 11-13: Colgajo de desplazamiento en la segunda fase quirúrgica con el objetivo de aportar mucosa queratinizada al área vestibular de las futuras restauraciones. 
Este diseño permite preservar las papilas de los dientes adyacentes.

- "Roll technique". Es un colgajo pediculado donde se realiza una trampilla palatina a espesor parcial, evitando las molestias en la cicatrización de esta zona y desplazando el tejido conectivo hacia vestibular $(42,50)$. Esta técnica está indicada para aumentar el volumen bucal de la mucosa periimplantaria, estando limitado este aumento a la cantidad de tejido palatino existente en la zona.

- Técnica de Palacci. Consigue regenerar tejido papilar en el área interproximal del os pilares transepiteliales, gracias a un diseño de incisión que permite el deslizamiento de parte del tejido hacia interproximal adaptado mediante sutura de los bordes (31).

Estas técnicas sirven de base para múltiples modificaciones que surgen para obtener una mejoría estética y funcional. No obstante, para los casos que requieran además un aporte de tejido de fuera del sitio quirúrgico periimplantario, podemos contar con las técnicas de injertos de tejidos blandos procedentes de distintas localizaciones de la cavidad oral. Lázaro y cols (24) analizan los criterios a seguir en la toma de decisiones en la segunda cirugía respecto a los tejidos blandos, y reservan las técnicas con autoinjertos para los casos donde existe una fenestración de la mucosa por la cabeza del implante, cuando existe una banda inadecuada de mucosa masticatoria, o bien cuando se pretende aumentar el volumen de los tejidos, consiguiendo además en estos casos mejorar el efecto estético.

Finalmente, debemos comentar los procedimientos de cicatrización gingival guiada que se realizan en la segunda fase quirúrgica. Tras la toma de impresiones en la primera cirugía corresponde en este segundo acto terapéutico la colocación de las prótesis provisionales que guiarán la cicatrización de los tejidos periimplantarios $(38,39)$.

\section{Durante la fase de mantenimiento}

La prevención de aparición de patología periimplantaria (mucositis y periimplantitis) se fundamenta en un correcto control de placa, monitorización profesional del estado de los tejidos periimplantarios, tratamientos que faciliten y permitan la higiene oral y la existencia de un entorno periimplantario adecuado (banda de mucosa queratinizada y profundidad del surco periimplantario) (51).

Ya han sido comentadas en este artículo las distintas ideas sobre la necesidad o no de una adecuada canti- dad de tejido queratinizado alrededor de los implantes $(18,23)$. A este respecto, parece estar bajo consenso el hecho de que esta porción de encía queratinizada proporciona confort y estabilidad a los pacientes en el uso de las de técnicas de higiene oral, permitiendo mantener libre de placa bacteriana los tejidos que rodean a los implantes $(51,52)$.

Por ello se recomiendan técnicas de autoinjertos de tejido blando en los casos donde se quiera aumentar esta banda de mucosa queratinizada, así como distintas técnicas que incluyen colgajos pediculados evitando una segunda zona quirúrgica. Por otro lado, las bolsas profundas periimplantarias están causadas generalmente por una discrepancia entre la posición de la cabeza de la fijación y la cresta ósea próxima a ésta, quedando el implante "enterrado" en el hueso que lo aloja, o bien por la presencia de excesivo tejido blando. Para resolver estas situaciones, los diferentes autores recomiendan acudir a técnicas de adelgazamiento de tejidos y colgajos de reposición apical, manteniendo en lo posible la banda de mucosa queratinizada, siendo deseable realizarlos antes de llegar a esta fase de mantenimiento $(53,54)$, así como el manejo de la cresta ósea de forma previa o simultánea a la colocación de los implantes con el fin de conseguir una posición final correcta de la cabeza del implante.

Otros problemas, como la hiperplasia gingival reactiva alrededor de los implantes por inflamación crónica, pueden ser resueltos mediante corrección del tejido bien a través de gingivectomía bien mediante la elevación de un colgajo que elimine el tejido hiperplásico (54).

\section{CONCLUSIONES}

1. Las similitudes existentes entre los tejidos periodontales y periimplantarios permiten aplicar conceptos y técnicas de la terapéutica periodontal a la práctica implantológica.

2. Actualmente, los criterios de éxito en implantología incluyen la consecución de unos objetivos estéticos, en un intento por imitar la naturaleza en el entorno periimplantario.

3. Las distintas localizaciones que albergarán los implantes (estéticas y estándar) y el tipo y técnica empleada (implantes de una pieza - una fase o implantes de dos piezas - dos fase) influyen notoriamente en la planificación y comportamiento del tratamiento implantológico.

4. Existen diferentes momentos de actuación sobre los tejidos periimplantarios. Así, en la fase previa se 
trabaja fundamentalmente sobre los tejidos duros; durante la inserción de los implantes, se intentará colocarlos en una posición idónea tridimensional guiada por las necesidades restauradoras. La segunda fase quirúrgica permite modificar los tejidos blandos uniendo técnicas de desplazamiento con técnicas de injertos, adaptándolos a los pilares de cicatrización usados en este momento. Finalmente, la fase de mantenimiento permite aplicar distintas técnicas para mejorar la calidad y cantidad de los tejidos periimplantarios según las necesidades.

\section{SUMIMARY}

Both periodontal and periimplant tissues share morphological and functional characteristics. This allows adapting common used periodontal techniques to the implantology. Nowadays, it is a normal practice to manage the soft periimplant tissues in a correct way, in order to improve the periimplant environment. The aim of this article is to make a literature review of all these concepts as well as the application of some periodontal techniques to the field of the implantology.

\section{KEY WORDS}

Implants, gingival grafts, soft tissue management.

\section{CORRESPONDECIA}

Leopoldo Mateos

Av. Eduardo Dato, $30-1{ }^{\circ} \mathrm{C}$

Tel. 9546478 90. 41005 Sevilla

e-mail: leomateos@mixmail.com

\section{BIBLIOGRAFÍA}

1. Adell R.; Leckholm, U.; Rockler, B. et al. A 15-year study of osseointegrated implants in the treatment of the edentulous jaw. Int J Oral Surg 1981;10: 387-416

2. Albrektsson, T.; Zarb, G.; Worthington, P. Eriksson, A.R. The long term efficacy of currently used dental implants. A review and proposed criteria of success. Int J Oral Maxillofac Implants 1986;1: 11-25
3. Adell, R.; Eriksson, B.; Lekholm, U. et al. A long-term follow-up study of osseointegrated implants in the treatment of totally edentulous jaw. Int J Oral Maxillof Implants 1990; 5: 347-59

4. Van Steenberghe, D.; Lekholm, U.; Bolender, C.; et al. The applicability of osseointegrated oral implants in the rehabilitation of partial edentulism. A prospective multicenter study on 558 fixtures. Int J Oral Maxillofac Implants 1990; 5: 272-81

5. ten Bruggenkate, CM.; van der Kwast, WA.; Oosterbeek, HS. Success criteria in oral implantology. A review of the literature. Int J Oral Implantol 1990; 7 (1): 45-51

6. Mombelli, A.; Lang, NP. Clinical parameters for the evaluation of dental implants. Periodontology 2000 1994; 4: 81-6

7. Lazzara, R. Managin the soft tissue margin: The key to implant esthetics. Pract Periodontics Aesthetic Dent 1993; 5: 81-7

8. Reiki, D.F. Restoring gingival harmony around single tooth implants. J Prosthet Dent 1995; 74: 47-50

9. James, R.A.; Kelln, E.A. A histopathological report of the nature of the epithelium and underlining connective tissue wich sorrounds implant posts. J Biomed Mat Res $1974 ; 5: 373$

10. Berglundh, T.; Lindhe, J.; Ericsson, I.; Marinello, C.; Liljenberg, B.; Thomsen, P. The soft tissue barrier at implant and teeth. Clin Oral Impl Res 1991; 2: 81-90

11. Moon, I.S.; Berglundh, T.; Abrahamsson, I.; Linder, E.; Lindhe, J. The barrier between the keratinized mucosa and the dental implant. An experimental study in the dog. J Clin Periodontol 1999; 26: 658-63

12. Lang, N.P.; Karring, T. (Ed). Proceedings of the lst European Workshop on Periodontology. Quintessence Publishing Co. 1994; 295-316

13. Berglundh, T.; Lindhe, J. Dimension of the periimplant mucosa. Biological width revisited. J Clin Periodontol 1996; 23: 971-3

14. Lavelle, Cl. Mucosal seal around endosseous dental implants. J Oral Implant 1981; 9: 357-71

15. James, R.A. y McKinney, R.V. Tejidos que rodean los implantes dentales. En: Misch, C.E. (ed.) Implantología contemporánea. Ed Mosby, 1995; 365-82

16. Mombelli, A.; Van Oosten, M.; Schurch, E.; Lang, N.P. The microbiota associated with successful or failing osseointegrated titanium implants. Oral Micro Inmunol 1987; 2: $145-51$ 
17. Rosenberg, E.S.; Toropsian, J.P.; Slots, J. Microbial differences in 2 clinically distinct types of failures of osseointegrated implants. Clin Oral Impl Res 1992; 3: 99-103

18. Nevins, M. Attached gingiva- Mucogingival therapy and restorative dentistry. Int J Periodont Rest Dent 1986; 6: 9-27

19. Apse, P.; Zarb, G.A.; Scmitt, A.; Lewis, D.W. The longitudinal efectiveness of osseointegrated dental implants. The Toronto study: Peri-implant mucosal response. Int J Periodont Rest Dent 1991; 11: 95-111

20. Karring, T.; Östergaard, E.; Löe, H. Conservation of tissue specificity after heterotopic transplantation of gingiva and alveolar mucosa. J Periodontol Res 1971; 6: 282-93

21. Karring, T.; Cumming, B.R.; Oliver, R.C.; Löe, H. The origin of granulation tissue and its impact on postoperative results of mucogingival surgery. J Periodontol 1975; 46: 577-85

22. Warrer, K.; Buser, D.; Lang, N.P.; Karring, T. Plaque-induced peri-implantitis in the presence or absence of keratinized mucosa. An experimental study in monkeys. Clin Oral Impl Res 1995; 6: 131-8

23. Wennström, J.L.; Bengazzi, F.; Lekholm, U. The influence of the masticatory mucosa on the periimplant soft tissue condition. Clin Oral Impl Res, 1994; 6: 131-8

24. Lázaro, P.J.; Herrero.M; Aranda,J.J.; Herrero, F. Enfoque periodontal de la segunda fase quirúrgica (II): Proceso de toma de decisiones en los tejidos blandos periimplantarios. Periodoncia 1999; 9 (5): 369-80

25. Hurzeler, M.B.; Dietmar, W. Peri-implant tissue management: Optimal timing for an aesthetic result. Pract Periodont Aesthet Dent 1996; 8: 857-69

26. Bahat, O.; Fontanesi, R.; Preston, J. Reconstruction of the hard and soft tissues for optimal placement of osseointegrated implants. Int J Periodont Rest Dent 1993; 13: 255-75

27. Cochran et al: Biologic width around titanium implants. A histometric analysis of the implanto-gingiva junction around unloaded and loaded nonsubmerged implants in the canine mandible. Clin Oral Implants Res 1997; 68: $186-98$

28. Hermann et al: Crestal bone changes around titanium implants. A radiographic evaluation of unloaded nonsubmerged and submerged implants in the canine mandible.J Periodontol Res 1997; 68: 1117-30

29. Weber et al. Comparisons of healed tissues adjacent to submerged and non-submerged unloaded titanium dental implants. A histometric study in beagle dogs. Clin Oral Implant Res 1996; 7: 11-9
30. Rosenquist, B. A comparison of various methods of soft tissue management following the immediate placement of implants into extraction sockets. Int J Oral Maxillofac Implants 1997; 12: 43-51

31. Palacci, P. Peri-implant soft tissue management: Papilla regeneration technique. En: Palacci, P. (ed.). Optimal implant positioning \& soft tissue management for the Bränemark system. Quintessence Books. Berlin, 1995: 59-70

32. Mathews, D. Tratamiento de los tejidos blandos alrededor de los implantes en zonas estéticas. Int J Periodont Rest Dent 2000; 20: 141-9

33. Seibert, J.S.; Louis, J. Soft tissue ridge augmentation utilizing a combination onlay-interpositionaL graft procedure:case report. Int J Periodont Rest Dent 1996; 16: 31 1-21

34. Langer,B.; Langer, L. Subepithelial connective tissue graft technique for root coverage. Journal of Periodontology 1985; 56: 715-20

35. Miller, P.D. Root coverage using a free soft tissue autograft following citric acid aplication. Int $\mathrm{j}$ Periodont Rest Dent 1982; 2: 65-70

36. Seibert, J.S. Reconstruction of deformed, partially edentulous ridges, using full thickness onlay grafts: I Technique and wound healing. Compendium of Continuing Education in General Dentistry 1983; 4: 43753

37. Bahat, O.; Handelman, M. Controlled tissue expansion in reconstructive periodontal surgery. Int J Periodont Rest Dent 1991; 11:32-47

38. Reiser, G.M.; Dornbush, J.R., Cohen, R. Iniciating restorative procedures at the first-stage implant surgery with a positional index: a case report. Int J Periodont Rest Dent 1992; 12: 279-93

39. Llobel, A.; Lobel, E. Modificación de los tejidos blandos periimplantarios: actuación en los estadíos quirúrgicos I y II. Periodoncia 1994; 4: 27-37

40. Tinti, C.; Parma-Benfenati, S. Coronally positioned palatal sliding flap. Int J Periodont Rest Dent 1995; 15: 298-310

41. Diví-Pujiol, J.; Rojo-Mirabet, E. Técnica del conjuntivo alveolar en los implantes de dientes unirradiculares. Periodoncia 1999; 9: 183-94

42. Abrams, L. Augmentation of the deformed residual edentolous ridge for fixed prosthesis. Comp Cont Dent Educ Dent 1980; 1: 205-14

43. Becker, W.; Becker, B. Guided tissue regeneration for implants placed into extraction sockets and for implants 
dehiscences: surgical techniques and case reports. Int J Periodont Rest Dent 1990; 10: 376-91

44. Chen, S.T.; Dahlin, C. Connective tissue grafting for primary closure of extraction sockets treated with an osteopromotive membrane technique: Surgical technique and clinical results. Int J Periodont Rest Dent 1996; 16: 349-55

45. Landsberg, C.J.; Socket seal surgery combined with inmediate implant placement: a novel approach for single tooth replacement. Int J Periodont Rest Dent 1997; 17: $141-9$

46. Arregui, Hurtado, I.; Sicilia Felechosa, A. y cols. Cirugía de sellado alveolar combinada con la colocación inmediata de implantes. Caso clínico. Periodoncia 1999; 9 (4): 275-82

47. Nemcovsky, C.; Moses, O.; Artzi, Z. Interproximal papillae reconstruction in maxillary implants.J Periodontol 2000; 71: 308-14

48. Hertel, R.C.; Blijdorp, P.A.; Kalk, W.; Baker, D.L. Stage 2 surgical techniques in endosseous implantation. Int $\mathrm{J}$ Oral Maxillofac Implants 1994: 9; 273-8
49. Jaffin, R.A. Fundamentos biológicos y clínicos para la operación de segunda fase y la conservación. Clin Odont Norteamérica 1989; 33: 699-716

50. Scharf, D.R.; Tarnow, D.P.; Modified roll technique for localized alveolar ridge augmentation. Int J Periodont Rest Dent 1992; 12: 415-25

51. Schroeder, A.; Von der Zypen, E.; Stick, H. et al. The reactions of bone, conective tissue, and epithelium to endosteal implants with titanium-sprayed surfaces. J Maxillofac Surg 1981; 9: 15-25

52. Van Steenberghe, D. Periodontal aspects of osseointegrated oral implants modum Bränemark. Dent Clin North Am 1988; $32: 3$ 55-70

53. Price, R.;Price, D. Restauración estética del implante dental de un solo diente utilizando un injerto de tejido conectivo subepitelial: informe de un caso con tres años de seguimiento. Int J Periodont Rest Dent 1999; 19: 93-101

54. Rapley, J.W.; Mills, M.P.;Wylam, J. Soft tissue management during implant maintenance. Int J Periodont Rest Dent 1992; 12: 373-81 